\title{
Predictive factors for major postoperative complications related to gastric conduit reconstruction in thoracoscopic esophagectomy for esophageal cancer: a case control study
}

Shinichiro Kobayashi', Kengo Kanetaka', Yasuhiro Nagata ${ }^{1,2}$, Masahiko Nakayama', Ryo Matsumoto', Mitsuhisa Takatsuki ${ }^{1}$ and Susumu Eguchi ${ }^{{ }^{*}}$

\begin{abstract}
Background: Regardless of developments in thoracoscopic esophagectomy (TE), postoperative complications relative to gastric conduit reconstruction are common after esophagectomy. The aim of the present study was to evaluate the predictive factors of major complications related to gastric conduit after TE.

Methods: From 2006 to 2015, 75 patients with esophageal cancer who underwent TE were evaluated to explore the predictive factors of major postoperative complications related to gastric conduit.

Results: Patients with major complications related to gastric conduit had a significantly longer postoperative hospital stay than patients without these complications $(P<0.01)$. Multivariate analysis demonstrated that three-field lymph node dissection (3FLND) and high serum levels of creatine phosphokinase (CPK) and C-reactive protein (CRP) at 1 postoperative day (1POD) after TE were significant predictive factors of major complications related to gastric conduit [odds ratio (OR) 5.37, 95\% confidence interval (Cl) 1.41-24.33, $P=0.02$; OR 5.40, 95\% Cl 1.60-20.20, $P<0.01$; OR 5.07, $95 \% \mathrm{Cl} 1.47-20.25, P=0.01$, respectively]. The incidence rates of major complications related to gastric conduit for 0,1 , 2 , and 3 predictive factors were $5.3 \%, 18.8 \%, 58.8 \%$, and $85.7 \%$, respectively $(P<0.01)$.
\end{abstract}

Conclusions: Two or more factors in 3FLND and the high levels of CPK and CRP at 1POD after TE were identified as the risk model for major complications related to gastric conduit after TE.

Trial registration: UMIN Clinical Trials Registry, ID: UMIN000024436, Registered date: Oct/17/2016.

Keywords: Esophageal cancer, Thoracoscopic surgery, Esophagectomy

\section{Background}

Although esophagectomy remains the curative treatment for patients with esophageal cancer, this procedure is accompanied by high incidences of complications [1,2]. The rates of morbidity and mortality after esophagectomy in large national databases were reported to be from $42 \%$ to $50 \%$ and $2.85 \%$ to $4.3 \%$, respectively [3-7]. Recent developments and improvements in

\footnotetext{
* Correspondence: sueguchi@nagasaki-u.ac.jp

'Department of Surgery, Nagasaki University Graduate School of Biomedical

Sciences, Sakamoto 1-7-1, Nagasaki 8528102, Japan

Full list of author information is available at the end of the article
}

thoracoscopic esophagectomy (TE) have reduced severe pulmonary complications after esophagectomy [8]. However, postoperative complications related to gastric conduit reconstruction are still common after esophagectomy [9]. Regarding cervical anastomotic complications after esophagectomy, leak and stricture formation are major issues $[10,11]$. In particular, ischemia of the proximal portion of the graft predisposes these patients to a high incidence of anastomotic complications after esophagectomy [12]. Less commonly, severe graft ischemia can lead to transmural necrosis. Thus, early diagnosis of an ischemic reaction may facilitate appropriate 
postoperative management and therapeutic intervention to prevent leakage, strictures and necrosis. The aim of the present study was to determine the predictive factors of severe gastric conduit-related postoperative complications.

\section{Methods}

\section{Patient population and operations}

From 2006 to 2015, 105 patients with esophageal cancer underwent esophagectomy and lymph node dissection at the Department of Surgery at Nagasaki University Hospital. Treatment plans for each patient were provided according to the clinical guidelines edited by the Japan Esophageal Society [13]. We chose open esophagectomy for the patients with severe adhesions in the chest or invasive neoplasia with lymph node involvement. Thirty patients were excluded because they required open esophagectomy with lymph node dissection. Seventy-five consecutive patients with esophageal cancer who underwent TE were retrospectively studied to evaluate the predictive factors for major complications related to gastric conduit after TE. The rules for classification and staging corresponded to the 7th edition of the International Union Against Cancer (UICC)/ American Joint Committee on Cancer (AJCC) Tumor Node Metastasis (TNM) staging system [14].

TE was performed from the right side in the left lateral position. Esophagectomy with lymphadenectomy in the mediastinum and around both recurrent nerves were performed. In the abdominal section, hand-assisted laparoscopic gastrectomy was performed to remove the mobilized esophagus with lymphadenectomy around the left gastric artery and aorta. After mobilization of the full stomach and esophagus, a gastric conduit was created by dividing the lesser curve of the stomach. The right gastric and right gastroepiploic artery provided the vascular supply to the created gastric conduit. In 73 patients, the gastric conduit was pulled up in the post-sternal route; in 2 patients, it was pulled up in the post-mediastinal route. The esophagogastrostomy was performed in the neck by end-to-side anastomosis. A $21-\mathrm{mm}$ or $25-\mathrm{mm}$ intraluminal stapler was used as the stapling device (CDH21, $\mathrm{CDH} 25$, Ethicon Ltd., Edinburgh, United Kingdom). The inserted part of the gastric conduit was crossed by linear stapling. All staple lines were oversewn.

Three-field lymph node dissection (3FLND) was performed in patients who had upper thoracic esophageal cancer or middle or lower thoracic esophageal cancer with lymph node metastasis in the neck region or around the right recurrent nerve [15].

This study was approved by the Ethics Committee of Nagasaki University Hospital (16082215). The written informed consent from the patients was waved from the Ethics Committee because the information on the opportunity to opt out was presented on the web site (http://www.mh.nagasaki-u.ac.jp/research/rinsho/patients/open_surgery2.html). This study was registered in the UMIN Clinical Trials Registry as UMIN000024436.

\section{Postoperative management}

The nasogastric tube was removed before anastomosis. On the first postoperative day (1POD), transintestinal nutrition was started from a jejunostomy feeding tube to prevent postoperative complications [16]. In the first three postoperative days, the patients without hoarseness and aspiration pneumonia started to drink fluids, followed by a soft diet.

\section{Definition of major postoperative complications related to gastric conduit reconstruction}

Major complications related to gastric conduit after TE were defined as anastomotic leakage, refractory anastomotic strictures, and gastric conduit necrosis. Anastomotic leakage was defined as fistula formation that required any invasive treatment (Clavien-Dindo classification of grade III or more). Anastomotic strictures were defined as the presence of a lumen requiring endoscopic balloon dilatation for the passage of a normal endoscope (9.2 $\mathrm{mm}$ diameter) with symptomatic dysphagia. Refractory esophageal strictures were defined as more than 5 sessions of balloon dilation 6 months after the operation [17, 18]. Gastric conduit necrosis was defined as a severe ischemic condition that required resection of the gastric graft.

\section{Statistical analysis}

The data are expressed as the means \pm standard deviation (SD) or medians and interquartile ranges (IQR). The relationships among major complications related to gastric conduit and age, body mass index (BMI), total operation time, operation time of thoracic surgery, and C-reactive protein (CRP) at 1POD were evaluated using Student's t-tests. The relationships between major postoperative complications related to gastric conduit reconstruction and other values were evaluated using Wilcoxon's tests. The relationships among anastomotic leakage and age, body mass index (BMI), total operation time, operation time of thoracic surgery, and C-reactive protein (CRP) at 1POD were evaluated using Student's t-tests. The relationships between anastomotic leakage and other values were evaluated using Wilcoxon's tests. The relationships among refractory anastomotic strictures and age, body mass index (BMI), total operation time, operation time of thoracic surgery, and C-reactive protein (CRP) at 1POD were evaluated using Student's t-tests. The relationships between refractory anastomotic strictures and other values were evaluated using Wilcoxon's tests. Receiver operating characteristic (ROC) curves and the area under the ROC curve (AUC) were used to assess the feasibility of using CRP and 
creatine phosphokinase (CPK) at 1POD as diagnostic tools for major complications related to gastric conduit [19]. The 95\% CI values greater than 0.5 for AUC indicated that prediction was better than chance [20]. The patients were divided into two groups according to the cut-off values of CRP and CPK at 1POD. The relationships of categorical clinical factors between the groups were analyzed using chi-square tests or Fisher's exact tests. A Fisher's exact test was applied if the theoretical frequency was less than five. Probability values (P) less than 0.05 were considered statistically significant. Multiple logistic regression (stepwise) models were developed, and odds ratios (OR) were used to evaluate predictive factors associated with major complications related to gastric conduit. The Cochrane-Armitage trend test was used to test for a linear trend in the proportion of patients who developed major postoperative complications related to gastric conduit reconstruction according to numbers of predictive factors. All statistical analyses were performed using SAS-JMP programs for Windows (SAS Institute Inc., Cary, NC).

\section{Results}

\section{Patient characteristics}

The clinical characteristics of the 75 patients, which included 18 females and 57 males, are summarized in Table 1. The average age of all patients was $61.3 \pm$ 8.1 years. The average BMI of all patients was $21.3 \pm 2.7$. Preoperative chemotherapy was performed in 51

Table 1 Patients' characteristics

\begin{tabular}{ll}
\hline Characteristic & Values \\
\hline Age (year) & $61.3 \pm 8.1$ \\
Gender (Male, Female) & 57,18 \\
BMI & $21.3 \pm 2.7$ \\
Preoperative chemotherapy & $51(68.0 \%)$ \\
TNM Stage (I, II(IIA, IIB), III(IIIA, & $28,19(7,12)$, \\
IIIB, IIIC), IV) & $24(13,7,4), 4$ \\
Total operating time (min) & $605 \pm 114$ \\
Operation time of thoracic & $331 \pm 73$ \\
surgery (min) & \\
Blood loss (g) & $370(270-600)$ \\
Blood transfusions & $7(9.3 \%)$ \\
3-field lymph node dissection & $23(30.7 \%)$ \\
Paroxysmal atrial fibrillation & $13(17.3 \%)$ \\
Vasopressor agents & $8(10.7 \%)$ \\
WBC (10^3/ $\mu$ ) at 1POD & $9.4(7.7-12.3)$ \\
CRP (10^4 $\mu$ g/L) at 1POD & $9.2 \pm 2.4$ \\
Lactic acid (mmol/L) at 1POD & $1.8 \pm 1.2$ \\
CPK (IU/L) at 1POD & $961(670-1504)$ \\
Postoperative hospital stay (days) & $27(20,39)$ \\
\hline
\end{tabular}

patients $(68.0 \%)$. Three patients $(4.0 \%)$ were diagnosed with adenocarcinoma, and 72 patients (96.0\%) were diagnosed with squamous cell carcinoma. According to the TNM classification, 47 patients (62.7\%) had tumors more advanced than stage I. 3FLND was performed in 23 patients (30.7\%). The average operating time was 605 $\pm 114 \mathrm{~min}$. The median estimated blood loss was $370 \mathrm{~g}$ (IQR 270-600). Blood transfusion was performed in 7 patients $(9.3 \%)$. The median length of the postoperative hospital stay was 27 days (IQR 20-39).

\section{Major complications related to gastric conduit reconstruction after TE}

The major complications related to gastric conduit after TE are summarized in Fig. 1. Twenty-three patients (30.7\%) developed major complications related to gastric conduit reconstruction after TE. Anastomotic leakage occurred in 17 patients who required drainage to manage infectious conditions. No patients died within 30 days after the operation due to anastomotic leakage. A stricture occurred in 33 patients who required endoscopic balloon dilation. Twenty patients developed simple esophageal strictures without other gastric conduit-related complications. Seven patients developed anastomotic leakage followed by simple esophageal strictures. Six patients developed refractory esophageal strictures. All patient with refractory strictures developed symptomatic strictures within 2 months after TE $(28.0 \pm 7.0$ days $)$. Two patients developed anastomotic leakage followed by refractory esophageal strictures. Two patients had gastric conduit necrosis, and one of these two patients died due to non-occlusive mesenteric ischemia after resection of the necrotic gastric conduit. The length of postoperative hospital stay after TE in the patients with major complications related to gastric conduit (39 days, IQR 28-47) was significantly longer than in those without these complications $(22$ days, IQR $19-28)(P<0.01)$.

\section{Predictive factors for the development of major complications related to gastric conduit after TE}

The predictive factors for developing major complications related to gastric conduit are shown in Table 2. In a univariate analysis, the predictive factors for developing major complications related to gastric conduit included age, 3FLND and levels of CRP and CPK at 1POD. The AUC for CRP and CPK at 1POD was 0.684 (95\%CI; $0.546-0.796)$ and 0.670 (95\%CI; 0.514-0.796). ROC curve analysis also identified the following cut-off values for CRP and CPK at 1POD: $9.6 \times 10^{\wedge} 4 \mu \mathrm{g} / \mathrm{L}$ and $1164 \mathrm{IU} / \mathrm{L}$, respectively (Fig. 2). At a threshold of $9.6 \times$ $10^{\wedge} 4 \mu \mathrm{g} / \mathrm{L}$ for CRP at $1 \mathrm{POD}$, the optimal sensitivity and specificity were $73.9 \%$ and $65.4 \%$, respectively, in patients developing major complications related to gastric conduit. At a threshold of $1164 \mathrm{IU} / \mathrm{L}$ for CPK at 




Fig. 1 Major complications related to gastric conduit reconstruction in 75 patients who underwent thoracoscopic esophagectomy. Seventeen patients developed anastomotic leakage. Refractory esophageal strictures were defined as more than 5 sessions of balloon dilation 6 months after the operation. Six patients developed refractory esophageal strictures. Two patients who had developed anastomotic leakage developed refractory esophageal strictures

1POD, the sensitivity and the specificity were $69.6 \%$ and $75.0 \%$, respectively.

The predictive factors for developing major complications related to gastric conduit are shown in Tables 3 and 4. In a univariate analysis, the predictive factors for developing anastomotic leakage related to gastric conduit included levels of CRP and CPK at 1POD.

When a multiple logistic regression analysis was performed to evaluate confounding factors, 3FLND and the levels of CPK and CRP at 1POD were found to be significantly associated with developing major complications related to gastric conduit (Table 5). The incidence rates of these complications for $0,1,2$, and 3 predictive factors were $5.3 \%(1 / 19), 18.8 \%$ (6/32), 58.8\% (10/17), and $85.7 \%(6 / 7)$, respectively (Fig. 3$)$. There was a strong trend toward increasing the prevalence of major complications related to gastric conduit based on the number of predictive factors $(P<0.01)$. The accuracy of 2 or more factors for major complications related to gastric conduit after TE was 0.800 .

\section{Discussion}

Our results showed that major postoperative complications related to gastric conduit were frequently present after TE and significantly prolonged the length of the postoperative hospital stay. We first evaluated the predictive factors for major complications related to gastric conduit after TE. Our study investigated the number of factors that could predict these complications after TE.

TE has been shown to reduce pulmonary complications and the length of postoperative hospital stay [8, 21, 22]. These results indicate a faster postoperative recovery in patients after TE than in patients after open esophagectomy. However, the morbidity after TE remains high

Table 2 Univariate analysis for factors predicting major complications related to gastric conduit after TE

\begin{tabular}{|c|c|c|c|}
\hline & \multicolumn{2}{|c|}{ Postoperative complications related to gastric conduit reconstruction } & \multirow[t]{2}{*}{$P$-value } \\
\hline & Negative $(n=52)$ & Positive $(n=23)$ & \\
\hline Age (years) & $62.9 \pm 7.2$ & $57.5 \pm 8.7$ & $<0.01$ \\
\hline Gender (Male, Female) & 37,15 & 20,3 & N.S. \\
\hline BMI & $21.4 \pm 2.7$ & $21.1 \pm 2.7$ & N.S. \\
\hline Preoperative chemotherapy & $21(40.4 \%)$ & $13(56.5 \%)$ & N.S. \\
\hline TNM Stage (I, II, III, IV) & $22,10,18,2$ & $6,9,6,2$ & N.S. \\
\hline Total operation time (min) & $604 \pm 113$ & $606 \pm 116$ & N.S. \\
\hline $\begin{array}{l}\text { Operation time of thoracic } \\
\text { surgery (min) }\end{array}$ & $337 \pm 77$ & $318 \pm 64$ & N.S. \\
\hline Blood loss (g) & $380(303-623)$ & $340(200-500)$ & N.S. \\
\hline Blood Transfusion & $5(9.6 \%)$ & $2(5.2 \%)$ & N.S. \\
\hline 3-field lymph node dissection & $12(23.1 \%)$ & $11(47.8 \%)$ & 0.03 \\
\hline Paroxysmal atrial fibrillation & $10(19.2 \%)$ & $3(13.0 \%)$ & N.S. \\
\hline Vasopressor agents & $5(9.6 \%)$ & $3(13.0 \%)$ & N.S. \\
\hline WBC $(10 \wedge 3 / \mu l)$ at $1 P O D$ & $9.7(8.2-12.8)$ & $8.9(7.0-11.5)$ & N.S. \\
\hline CRP $(10 \wedge 4 \mu \mathrm{g} / \mathrm{L})$ at $1 \mathrm{POD}$ & $8.7 \pm 0.3$ & $10.3 \pm 0.5$ & $<0.01$ \\
\hline Lactic acid (mmol/L) at 1POD & $1.4(1.1-1,8)$ & $2.1(1.2-2.7)$ & N.S. \\
\hline CPK (IU/L) at $1 \mathrm{POD}$ & $890(620-1309)$ & $1277(675-2041)$ & 0.02 \\
\hline Postoperative hospital stay (days) & $22(19-28)$ & $39(28-47)$ & $<0.01$ \\
\hline
\end{tabular}




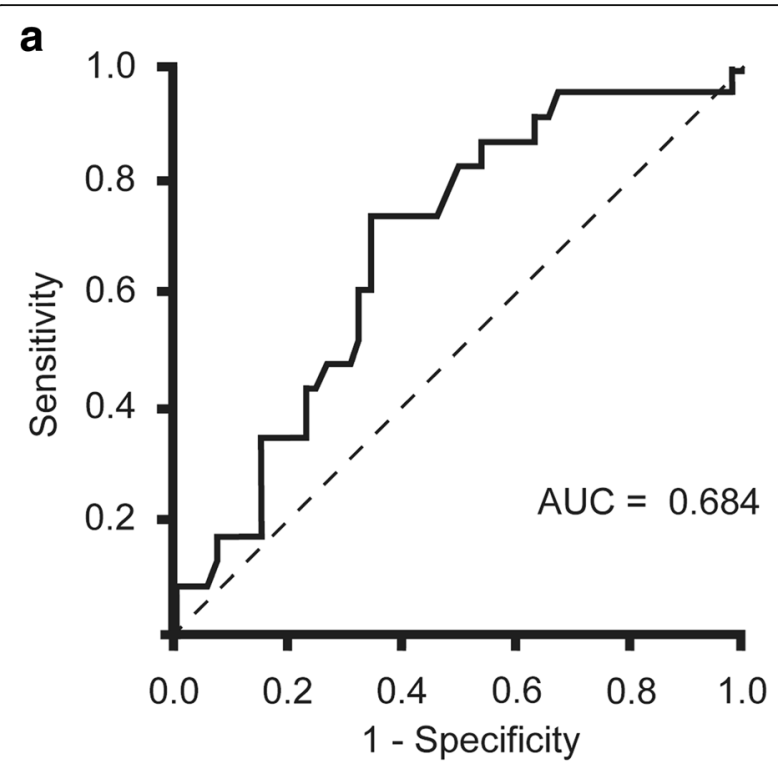

b

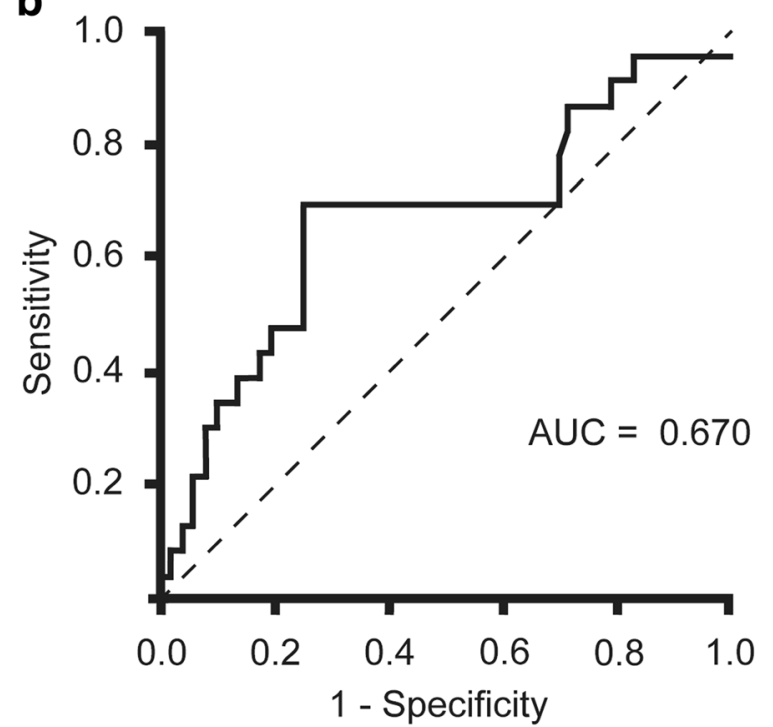

Fig. 2 ROC curve analysis of CRP (a) and CPK (b) at the first postoperative day after thoracoscopic esophagectomy. At a threshold of $9.6 \times 10^{4} \mu \mathrm{g} / \mathrm{L} C R P$ at $1 P O D$, the optimal sensitivity and specificity were $73.9 \%$ and $65.4 \%$, respectively, in patients developing major postoperative complications related to gastric conduit reconstruction. At a threshold of $1164 \mathrm{IU} / \mathrm{L} \mathrm{CPK}$ at 1POD, the sensitivity and the specificity were $69.6 \%$ and $75.0 \%$, respectively, in patients developing major postoperative complications related to gastric conduit reconstruction. $\mathrm{ROC}$, receiver operating characteristic; $\mathrm{CRP}, \mathrm{C}$-reactive protein; POD, postoperative days; CPK, creatine phosphokinase. AUC, area under the ROC curve; $\mathrm{Cl}$, confidence interval

(approximately 30-40\%) [1, 2, 23], and preventing gastric conduit-related complications after TE remains difficult. Our data are similar to the Japanese nationwide web-based database and other articles regarding BMI, operation time, the rate of anastomotic leakage, and postoperative days $[5,7,24,25]$. There is a therapeutic benefit in predicting the postoperative complications of gastric conduit reconstruction after TE. The 3 predictive factors identified in this study may facilitate the decision to delay oral intake and perform early interventional treatments, such as re-operation, drainage and dilation, after TE.

Our study showed that 3FLND led to major complications related to gastric conduit. Lymph node dissection for thoracic esophageal cancer is controversial, and whether 3FLND or 2-field lymph node dissection (2FLND) is better remains a subject of debate [26-29]. The advantages and disadvantages of 3FLND remain controversial when compared to 2FLND of esophagectomy [30, 31]. One meta-analysis showed that 3FLND improves the overall survival rate but leads to more major complications than 2FLND [32, 33]. Anastomotic leakage is likely linked to cervical lymph node dissection due to inflammation and reduced angiogenesis around the anastomotic area [34], which strongly supports our results. However, future studies should determine whether 3FLND or 2FLND is better according to the patient's physical condition and tumor staging.

The retrosternal route in almost all cases was applied to the gastric conduit of reconstruction after esophagectomy. There are several advantages of this method for the management of local recurrence, including fewer complications in gastric conduit and a short route in the retrosternal route of reconstruction [13, 35, 36]. In RCT studies, both posterior and anterior mediastinal routes of reconstruction were associated with similar surgical outcomes after esophagectomy for cancer [37]. In the Japanese registry, the retrosternal route of reconstruction was selected in $34 \%$ of patients, although the posterior mediastinal route was used for reconstruction in $41.3 \%$ of patients [38]. Thus, the route of reconstruction remains controversial.

High CRP levels after esophagectomy are reported to precede the clinical diagnosis of postoperative infectious complications [39, 40]. With regard to postoperative infectious complications, there is no difference between patients with and without postoperative infectious complications on 1POD [39, 40]. Consistent with previous reports, our results showed that some infectious complications developed but hardly affected the serum CRP levels on 1POD after TE. Moreover, TE minimizes lung injury and severe pulmonary complications after esophagostomy. Thus, high CRP levels on 1POD may be induced in response to surgical trauma and gastric conduit ischemic conditions after TE. We also identified high CPK levels as a predictive factor for major complications related to gastric conduit after TE. CPK was also reported as a biomarker of ischemic small bowel disease in animal models $[41,42]$. CPK may reflect not only 
Table 3 Univariate analysis for factors predicting anastomotic leakage after TE

\begin{tabular}{|c|c|c|c|}
\hline & \multicolumn{2}{|c|}{ Anastomotic leakage } & \multirow[t]{2}{*}{$P$-value } \\
\hline & Negative $(n=58)$ & Positive $(n=17)$ & \\
\hline Age (years) & $62.3 \pm 7.8$ & $57.8 \pm 8.3$ & N.S. \\
\hline Gender (Male, Female) & 43,15 & 14,3 & N.S. \\
\hline $\mathrm{BMl}$ & $21.3 \pm 2.7$ & $21.1 \pm 2.8$ & N.S. \\
\hline Preoperative chemotherapy & $25(43.1 \%)$ & $9(52.9 \%)$ & N.S. \\
\hline TNM Stage (I, II, III, IV) & $22,13,20,3$ & $6,6,4,1$ & N.S. \\
\hline Total operation time (min) & $608 \pm 112$ & $594 \pm 122$ & N.S. \\
\hline $\begin{array}{l}\text { Operation time of thoracic } \\
\text { surgery (min) }\end{array}$ & $338 \pm 76$ & $305 \pm 60$ & N.S. \\
\hline Blood loss (g) & $380(290-608)$ & $350(235-615)$ & N.S. \\
\hline Blood Transfusion & $6(10.3 \%)$ & $1(5.9 \%)$ & N.S. \\
\hline 3-field lymph node dissection & $15(25.9 \%)$ & $8(47.1 \%)$ & N.S. \\
\hline Paroxysmal atrial fibrillation & $10(17.2 \%)$ & $3(17.7 \%)$ & N.S. \\
\hline Vasopressor agents & $7(12.1 \%)$ & $1(5.9 \%)$ & N.S. \\
\hline $\mathrm{WBC}(10 \wedge 3 / \mu \mathrm{l})$ at $1 \mathrm{POD}$ & $9.7(8.2-12.8)$ & $8.9(7.0-11.5)$ & N.S. \\
\hline $\mathrm{CRP}(10 \wedge 4 \mu \mathrm{g} / \mathrm{L})$ at $1 \mathrm{POD}$ & $8.7 \pm 2.4$ & $10.5 \pm 2.0$ & $<0.01$ \\
\hline Lactic acid (mmol/L) at 1POD & $1.5(1.1-2.0)$ & $2.0(0.7-2.6)$ & N.S. \\
\hline CPK (IU/L) at $1 \mathrm{POD}$ & $919.5(629-1400)$ & $1232(683-2177)$ & $<0.05$ \\
\hline Postoperative hospital stay (days) & $22(19-28)$ & $42(30-47)$ & $<0.01$ \\
\hline
\end{tabular}

Table 4 Univariate analysis for factors predicting refractory anastomotic strictures after TE

\begin{tabular}{|c|c|c|c|}
\hline & \multicolumn{2}{|c|}{ Refractory anastomotic strictures } & \multirow{2}{*}{$\begin{array}{l}P- \\
\text { value }\end{array}$} \\
\hline & Negative $(n=69)$ & Positive $(n=6)$ & \\
\hline Age (years) & $61.4 \pm 8.2$ & $59.0 \pm 6.4$ & N.S. \\
\hline Gender (Male, Female) & 51,18 & 6,0 & N.S. \\
\hline $\mathrm{BMI}$ & $21.4 \pm 2.7$ & $21.1 \pm 2.7$ & N.S. \\
\hline Preoperative chemotherapy & $39(56.5 \%)$ & $2(33.3 \%)$ & N.S. \\
\hline TNM Stage (I, II, III, IV) & $27,16,22,4$ & $1,4,1,0$ & N.S. \\
\hline Total operation time (min) & $604 \pm 113$ & $606 \pm 116$ & N.S. \\
\hline $\begin{array}{l}\text { Operation time of thoracic } \\
\text { surgery (min) }\end{array}$ & $331 \pm 75$ & $329 \pm 55$ & N.S. \\
\hline Blood loss (g) & $380(303-623)$ & $340(200-500)$ & N.S. \\
\hline Blood Transfusion & $6(8.7 \%)$ & $1(16.7 \%)$ & N.S. \\
\hline 3-field lymph node dissection & $22(29.3 \%)$ & $1(16.7 \%)$ & N.S. \\
\hline Paroxysmal atrial fibrillation & $12(17.4 \%)$ & $1(16.7 \%)$ & N.S. \\
\hline Vasopressor agents & $7(10.1 \%)$ & $1(16.7 \%)$ & N.S. \\
\hline WBC $(10 \wedge 3 / \mu l)$ at $1 P O D$ & $9.7(8.2-12.8)$ & $8.9(7.0-11.5)$ & N.S. \\
\hline $\mathrm{CRP}(10 \wedge 4 \mu \mathrm{g} / \mathrm{L})$ at $1 \mathrm{POD}$ & $9.0 \pm 2.3$ & $10.9 \pm 3.6$ & N.S. \\
\hline Lactic acid (mmol/L) at 1POD & $1.4(1.1-1,8)$ & $2.1(1.2-2.7)$ & N.S. \\
\hline CPK (IU/L) at $1 \mathrm{POD}$ & $890(620-1309)$ & $1214(675-2041)$ & N.S. \\
\hline Postoperative hospital stay (days) & $20(20-35)$ & $41(25-61)$ & N.S. \\
\hline
\end{tabular}


Table 5 Multivariate analysis for factors predicting major complications related to gastric conduit after TE

\begin{tabular}{llll}
\hline & Odds ratio & $P$-value & $95 \% \mathrm{Cl}$ \\
\hline Age (years) & 0.92 & 0.06 & $(0.85-1.00)$ \\
3-field lymph node dissection & 5.37 & 0.02 & $(1.41-24.33)$ \\
CRP at 1POD (high / low) & 5.07 & 0.01 & $(1.47-20.25)$ \\
CPK at 1POD (high / low) & 5.40 & $<0.01$ & $(1.60-20.20)$ \\
\hline
\end{tabular}

ischemic changes in the muscle layer of the gastric conduit but also inflammation around the muscle layers of the neck, as the CPK level is not generally a good biomarker for bowel ischemia [43]. In open esophagectomy, high CPK levels may be observed in patients without major complications related to gastric conduit because of the large incision in the thoracic field.

Postoperative endoscopic examination is a highly accurate method to evaluate reconstruction of the gastric conduit after esophagectomy [12, 44-46]. However, endoscopic examination is complex and invasive after esophagectomy. Thus, these predictive factors after TE are useful to select patients who may benefit from endoscopic examination.

Published results have been inconclusive as to which anastomotic technique is ideal for esophagectomy [9, 47-51]. Thus, surgeons base their choice of anastomotic technique on personal preference. We applied end-to-side anastomosis with an intraluminal stapler in this study. Cervical anastomosis using a stapler more frequently causes anastomotic strictures than other techniques [9, 52]. However, almost all patients show improved anastomotic strictures after three or fewer dilatations within several months [52]. Thus, the ischemic condition of the gastric conduit may influence

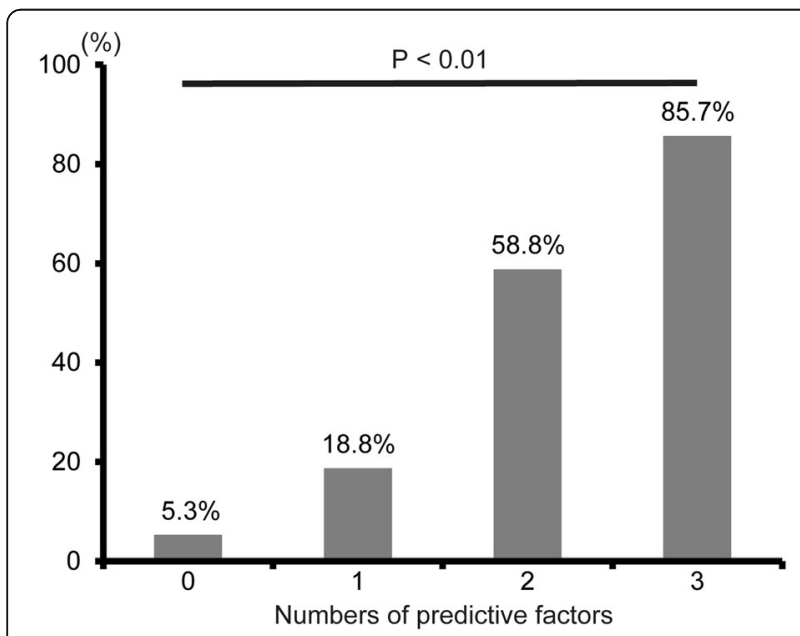

Fig. 3 Prevalence of major complications related to gastric conduit reconstruction compared according to the number of predictive factors after thoracoscopic esophagectomy. P-value based on the Cochrane-Armitage trend test anastomotic healing in patients who develop refractory strictures $[49,52]$.

Our study has several limitations. First, our study was performed at a single institution, and further prospective studies are needed at multiple institutions. Second, the accuracy of the predictive factors is somewhat low. Third, almost all patients were diagnosed with squamous cell carcinoma. Thus, transthoracic extended radical esophagectomy with 3-field lymph node dissection is included in our data. The invasive procedure caused delayed recovery of the patients and resulted in a relatively long postoperative stay. 2-field lymphadenectomy using the Ivor Lewis procedure or trans-hiatal esophagectomy is more commonly performed for esophageal adenocarcinoma in Western countries [5]. Because differences in oncological features and health insurance systems may result in differences in surgical procedures and postoperative stay, it remains unclear whether the predictive factors are applicable to assess patients in Western countries [7, 53]. Fourth, delayed emptying of the gastric conduit was eliminated because there were no patients with endoscopic pyloric dilation and surgical intervention [54, 55]. Despite these limitations, this study is the first to address major complications related to gastric conduit after TE.

\section{Conclusions}

In conclusion, 3FLND and the levels of CPK and CRP at 1POD after TE were predictive factors for major complications related to gastric conduit. Two or more factors in 3FLND and the high levels of CPK and CRP at 1POD after TE were identified as the risk model for major complications related to gastric conduit after TE.

\section{Abbreviations}

3FLND: Three-field lymph node dissection; AUC: The area under the ROC curve; BMl: Body mass index; Cl: Confidence interval; CPK: Creatine phosphokinase; CRP: C-reactive protein; IQR: Interquartile ranges; OR: Odds ratio; POD: Postoperative day; ROC: Receiver operating characteristic; SD: Standard deviation; TE: Thoracoscopic esophagectomy

\section{Acknowledgements}

The authors thank Shuntaro Sato, who helped with the statistical analysis.

\section{Funding}

This study was partially supported in writing and editing the manuscript by a Grant-in-Aid for Scientific Research from the Japan Society for the Promotion of Science (15H06503 and 17 K16569 Shinichiro Kobayashi).

\section{Availability of data and materials}

The datasets generated and analyzed during the current study are available from the corresponding author on reasonable request.

\section{Authors' contributions}

SK. designed the study, analyzed data, and wrote the initial draft of the manuscript. KK. and YN. especially contributed to interpretation of data and supervised the patient treatments. MN., RM., and MT. especially participated in the discussion and assisted in the preparation of the manuscript. SE. supervised the patient treatments, and especially assisted in editing the manuscript. All other authors have contributed to data collection and interpretation, and critically reviewed the manuscript. All authors approved 
the final version of the manuscript, and agree to be accountable for all aspects of the work in ensuring that questions related to the accuracy or integrity of any part of the work are appropriately investigated and resolved.

\section{Ethics approval and consent to participate}

This study was approved by the Ethics Committee of Nagasaki University Hospital (16082215). The written informed consent from the patients was waved from the Ethics Committee because the information on the opportunity to opt out was presented on the web site (http://www.mh nagasaki-u.ac.jp/research/rinsho/patients/open_surgery2.html).

\section{Consent for publication}

Not applicable. Individual identifying data were not included in this manuscript.

\section{Competing interests}

Shinichiro Kobayashi, Kengo Kanetaka, Yasuhiro Nagata, Masahiko Nakayama, Ryo Matsumoto, Mitsuhisa Takatsuki, and Susumu Eguchi do not have any financial relationships relevant to this publication to disclose.

\section{Publisher's Note}

Springer Nature remains neutral with regard to jurisdictional claims in published maps and institutional affiliations.

\section{Author details}

${ }^{1}$ Department of Surgery, Nagasaki University Graduate School of Biomedical Sciences, Sakamoto 1-7-1, Nagasaki 8528102, Japan. ${ }^{2}$ Center for Comprehensive Community Care Education, Nagasaki University Graduate School of Biomedical Sciences, Sakamoto 1-12-4, Nagasaki, Japan.

\section{Received: 12 July 2017 Accepted: 23 February 2018} Published online: 06 March 2018

\section{References}

1. Verhage RJ, Hazebroek EJ, Boone J, Van Hillegersberg R. Minimally invasive surgery compared to open procedures in esophagectomy for cancer: a systematic review of the literature. Minerva Chir. 2009;64(2):135-46.

2. Blencowe NS, Strong S, McNair AG, Brookes ST, Crosby T, Griffin SM, Blazeby JM. Reporting of short-term clinical outcomes after esophagectomy: a systematic review. Ann Surg. 2012;255(4):658-66.

3. Dhungel B, Diggs BS, Hunter JG, Sheppard BC, Vetto JT, Dolan JP. Patient and peri-operative predictors of morbidity and mortality after esophagectomy: American College of Surgeons National Surgical Quality Improvement Program (ACS-NSQIP), 2005-2008. J Gastrointest Surg. 2010; 14(10):1492-501.

4. Mamidanna R, Bottle A, Aylin P, Faiz O, Hanna GB. Short-term outcomes following open versus minimally invasive esophagectomy for cancer in England: a population-based national study. Ann Surg. 2012;255(2):197-203.

5. Takeuchi H, Miyata H, Gotoh M, Kitagawa Y, Baba H, Kimura W, Tomita N, Nakagoe T, Shimada M, Sugihara $K$, et al. A risk model for esophagectomy using data of 5354 patients included in a Japanese nationwide web-based database. Ann Surg. 2014;260(2):259-66.

6. Yerokun BA, Sun Z, Yang CJ, Gulack BC, Speicher PJ, Adam MA, D'Amico TA Onaitis MW, Harpole DH, Berry MF, et al. Minimally invasive versus open Esophagectomy for esophageal cancer: a population-based analysis. Ann Thorac Surg. 2016;102(2):416-23.

7. Takeuchi H, Miyata H, Ozawa S, Udagawa H, Osugi H, Matsubara H, Konno $H$, Seto $Y$, Kitagawa $Y$. Comparison of short-term outcomes between open and minimally invasive Esophagectomy for esophageal cancer using a Nationwide database in Japan. Ann Surg Oncol. 2017;24(7):1821-7.

8. Findlay JM, Gillies RS, Millo J, Sgromo B, Marshall RE, Maynard ND. Enhanced recovery for esophagectomy: a systematic review and evidence-based guidelines. Ann Surg. 2014;259(3):413-31.

9. Honda M, Kuriyama A, Noma H, Nunobe S, Furukawa TA. Hand-sewn versus mechanical esophagogastric anastomosis after esophagectomy: a systematic review and meta-analysis. Ann Surg. 2013:257(2):238-48.

10. Cassivi SD. Leaks, strictures, and necrosis: a review of anastomotic complications following esophagectomy. Semin Thorac Cardiovasc Surg 2004;16(2):124-32.

11. Nishikawa K, Fujita T, Yuda M, Yamamoto S, Tanaka Y, Matsumoto A Tanishima Y, Yano F, Mitsumori N, Yanaga K. Early postoperative endoscopy for targeted management of patients at risks of anastomotic complications after esophagectomy. Surgery. 2016;160(5):1294-301.

12. Fujiwara H, Nakajima Y, Kawada K, Tokairin Y, Miyawaki Y, Okada T, Nagai K, Kawano T. Endoscopic assessment 1 day after esophagectomy for predicting cervical esophagogastric anastomosis-relating complications. Surg Endosc. 2016;30(4):1564-71.

13. Kuwano H, Nishimura $Y$, Oyama T, Kato H, Kitagawa $Y$, Kusano M, Shimada H, Takiuchi H, Toh Y, Doki Y, et al. Guidelines for diagnosis and treatment of carcinoma of the esophagus April 2012 edited by the Japan esophageal society. Esophagus. 2015;12(1):1-30.

14. Edge SB BD, Compton CC, Fritz AG, Greene FL, Trotti A. AJCC cancer staging manual. 7th ed. New York: Springer-Verlag; 2009. p.103-15.

15. Li H, Yang S, Zhang Y, Xiang J, Chen $H$. Thoracic recurrent laryngeal lymph node metastases predict cervical node metastases and benefit from threefield dissection in selected patients with thoracic esophageal squamous cel carcinoma. J Surg Oncol. 2012;105(6):548-52.

16. Lewis SJ, Andersen HK, Thomas S. Early enteral nutrition within $24 \mathrm{~h}$ of intestinal surgery versus later commencement of feeding: a systematic review and meta-analysis. J Gastrointest Surg. 2009:13(3):569-75.

17. Kochman ML, McClave SA, Boyce HW. The refractory and the recurrent esophageal stricture: a definition. Gastrointest Endosc. 2005:62(3):474-5.

18. Yano T, Yoda Y, Nomura S, Toyosaki K, Hasegawa H, Ono H, Tanaka M, Morimoto $\mathrm{H}$, Horimatsu T, Nonaka S, et al. Prospective trial of biodegradable stents for refractory benign esophageal strictures after curative treatment of esophageal cancer. Gastrointest Endosc. 2017;86(3):492-9.

19. Hanley JA, McNeil BJ. The meaning and use of the area under a receiver operating characteristic (ROC) curve. Radiology. 1982;143(1):29-36.

20. Lasko TA, Bhagwat JG, Zou KH, Ohno-Machado L. The use of receiver operating characteristic curves in biomedical informatics. J Biomed Inform 2005:38(5):404-15.

21. Biere SS, van Berge Henegouwen MI, Maas KW, Bonavina L, Rosman C, Garcia JR, Gisbertz SS, Klinkenbijl JH, Hollmann MW, de Lange ES, et al. Minimally invasive versus open oesophagectomy for patients with oesophageal cancer: a multicentre, open-label, randomised controlled trial. Lancet. 2012;379(9829):1887-92.

22. Straatman J, van der Wielen N, Cuesta MA, Daams F, Roig Garcia J, Bonavina L, Rosman C, van Berge Henegouwen MI, Gisbertz SS, van der Peet DL. Minimally invasive versus open esophageal resection: three-year follow-up of the previously reported randomized controlled trial: the TIME trial. Ann Surg. 2017;266(2):232-6.

23. Decker $G$, Coosemans W, De Leyn P, Decaluwe H, Nafteux P, Van Raemdonck D, Lerut T. Minimally invasive esophagectomy for cancer. Eur J Cardiothorac Surg. 2009;35(1):13-21.

24. Hirahara N, Matsubara T, Mizota Y, Ishibashi S, Tajima Y. Prognostic value of preoperative inflammatory response biomarkers in patients with esophagea cancer who undergo a curative thoracoscopic esophagectomy. BMC Surg. 2016:16(1):66.

25. Baba Y, Yoshida N, Shigaki H, Iwatsuki M, Miyamoto $Y$, Sakamoto $Y$, Watanabe M, Baba H. Prognostic impact of postoperative complications in 502 patients with surgically resected esophageal squamous cell carcinoma: a retrospective single-institution study. Ann Surg. 2016;264(2):305-11.

26. Tsurumaru M, Kajiyama Y, Udagawa H, Akiyama H. Outcomes of extended ymph node dissection for squamous cell carcinoma of the thoracic esophagus. Ann Thorac Cardiovasc Surg. 2001;7(6):325-9.

27. Tachibana M, Kinugasa S, Yoshimura H, Shibakita M, Tonomoto Y, Dhar DK, Nagasue N. Clinical outcomes of extended esophagectomy with three-field lymph node dissection for esophageal squamous cell carcinoma. Am J Surg. 2005;189(1):98-109.

28. Hsu WH, Hsu PK, Hsieh CC, Huang CS, Wu YC. The metastatic lymph node number and ratio are independent prognostic factors in esophageal cancer. J Gastrointest Surg. 2009;13(11):1913-20.

29. Japan Esophageal Society. Japanese classification of esophageal cancer. 11 th edition, part I. Esophagus. 2017;17(1):1-36.

30. Lerut T, Nafteux P, Moons J, Coosemans W, Decker G, De Leyn P, Van Raemdonck D, Ectors N. Three-field lymphadenectomy for carcinoma of the esophagus and gastroesophageal junction in 174 R0 resections: impact on staging, disease-free survival, and outcome: a plea for adaptation of TNM classification in upper-half esophageal carcinoma. Ann Surg. 2004;240(6): 962-74.

31. Chen J, Wu S, Zheng X, Pan J, Zhu K, Chen Y, Li J, Liao L, Lin Y, Liao Z Cervical lymph node metastasis classified as regional nodal staging in 
thoracic esophageal squamous cell carcinoma after radical esophagectomy and three-field lymph node dissection. BMC Surg. 2014;14:110.

32. Ye T, Sun Y, Zhang Y, Chen $\mathrm{H}$. Three-field or two-field resection for thoracic esophageal cancer: a meta-analysis. Ann Thorac Surg. 2013;96(6):1933-41.

33. Ma GW, Situ DR, Ma QL, Long H, Zhang LJ, Lin P, Rong TH. Three-field vs two-field lymph node dissection for esophageal cancer: a meta-analysis. World J Gastroenterol. 2014;20(47):18022-30.

34. Zheng QF, Wang JJ, Ying MG, Liu SY. Omentoplasty in preventing anastomotic leakage of oesophagogastrostomy following radical oesophagectomy with three-field lymphadenectomy. Eur J Cardiothorac Surg. 2013;43(2):274-8.

35. Chen H, Lu JJ, Zhou J, Zhou X, Luo X, Liu Q, Tam J. Anterior versus posterior routes of reconstruction after esophagectomy: a comparative anatomic study. Ann Thorac Surg. 2009;87(2):400-4.

36. $\mathrm{Hu} H, \mathrm{Ye} T$, Tan $\mathrm{D}, \mathrm{Li} \mathrm{H}$, Chen $\mathrm{H}$. Is anterior mediastinum route a shorter choice for esophageal reconstruction? A comparative anatomic study. Eur J Cardiothorac Surg. 2011;40(6):1466-9.

37. Urschel JD, Urschel DM, Miller JD, Bennett WF, Young JE. A meta-analysis of randomized controlled trials of route of reconstruction after esophagectomy for cancer. Am J Surg. 2001;182(5):470-5.

38. Tachimori $Y$, Ozawa S, Numasaki H, Ishihara R, Matsubara H, Muro K, Oyama T, Toh Y, Udagawa H, Uno T. Comprehensive registry of esophageal cancer in Japan, 2010. Esophagus. 2017;14(3):189-214.

39. Miki Y, Toyokawa T, Kubo N, Tamura T, Sakurai K, Tanaka H, Muguruma K, Yashiro M, Hirakawa K, Ohira M. C-reactive protein indicates early stage of postoperative infectious complications in patients following minimally invasive Esophagectomy. World J Surg. 2017;41(3):796-803.

40. Hoeboer SH, Groeneveld AB, Engels N, van Genderen M, Wijnhoven BP, van Bommel J. Rising C-reactive protein and procalcitonin levels precede early complications after esophagectomy. J Gastrointest Surg. 2015;19(4):613-24.

41. Kanda T, Nakatomi $Y$, Ishikawa $H$, Hitomi M, Matsubara $Y$, Ono T, Muto T. Intestinal fatty acid-binding protein as a sensitive marker of intestinal ischemia. Dig Dis Sci. 1992;37(9):1362-7.

42. Kanda T, Tsukahara A, Ueki K, Sakai Y, Tani T, Nishimura A, Yamazaki T, Tamiya Y, Tada T, Hirota M, et al. Diagnosis of ischemic small bowel disease by measurement of serum intestinal fatty acid-binding protein in patients with acute abdomen: a multicenter, observer-blinded validation study. J Gastroenterol. 2011;46(4):492-500

43. van der Voort PH, Westra B, Wester JP, Bosman RJ, van Stijn I, Haagen IA, Loupatty FJ, Rijkenberg S. Can serum L-lactate, D-lactate, creatine kinase and I-FABP be used as diagnostic markers in critically ill patients suspected for bowel ischemia. BMC Anesthesiol. 2014;14:111.

44. Oezcelik A, Banki F, Ayazi S, Abate E, Zehetner J, Sohn HJ, Hagen JA, DeMeester SR, Lipham JC, Palmer SL, et al. Detection of gastric conduit ischemia or anastomotic breakdown after cervical esophagogastrostomy: the use of computed tomography scan versus early endoscopy. Surg Endosc. 2010;24(8):1948-51.

45. Page RD, Asmat A, McShane J, Russell GN, Pennefather SH. Routine endoscopy to detect anastomotic leakage after esophagectomy. Ann Thorac Surg. 2013;95(1):292-8.

46. Schaible A, Sauer P, Hartwig W, Hackert T, Hinz U, Radeleff B, Büchler MW, Werner J. Radiologic versus endoscopic evaluation of the conduit after esophageal resection: a prospective, blinded, intraindividually controlled diagnostic study. Surg Endosc. 2014;28(7):2078-85.

47. Dewar L, Gelfand G, Finley RJ, Evans K, Inculet R, Nelems B. Factors affecting cervical anastomotic leak and stricture formation following esophagogastrectomy and gastric tube interposition. Am J Surg. 1992; 163(5):484-9.

48. Walther B, Johansson J, Johnsson F, Von Holstein CS, Zilling T. Cervical or thoracic anastomosis after esophageal resection and gastric tube reconstruction: a prospective randomized trial comparing sutured neck anastomosis with stapled intrathoracic anastomosis. Ann Surg. 2003;238(6): 803-14

49. Zhang YS, Gao BR, Wang HJ, Su YF, Yang YZ, Zhang JH, Wang C. Comparison of anastomotic leakage and stricture formation following layered and stapler oesophagogastric anastomosis for cancer: a prospective randomized controlled trial. J Int Med Res. 2010:38(1):227-33.

50. Kim RH, Takabe K. Methods of esophagogastric anastomoses following esophagectomy for cancer: a systematic review. J Surg Oncol. 2010; 101(6):527-33.

51. Xu QR, Wang KN, Wang WP, Zhang K, Chen LQ. Linear stapled esophagogastrostomy is more effective than hand-sewn or circular stapler in prevention of anastomotic stricture: a comparative clinical study. J Gastrointest Surg. 2011;15(6):915-21.

52. Law S, Fok M, Chu KM, Wong J. Comparison of hand-sewn and stapled esophagogastric anastomosis after esophageal resection for cancer: a prospective randomized controlled trial. Ann Surg. 1997;226(2):169-73.

53. Muramatsu N, Liang J. Hospital length of stay in the United States and Japan: a case study of myocardial infarction patients. Int J Health Serv. 1999;29(1):189-209.

54. Akkerman RD, Haverkamp L, van Hillegersberg R, Ruurda JP. Surgical techniques to prevent delayed gastric emptying after esophagectomy with gastric interposition: a systematic review. Ann Thorac Surg. 2014;98(4):1512-9.

55. Poghosyan T, Gaujoux S, Chirica M, Munoz-Bongrand N, Sarfati E, Cattan P. Functional disorders and quality of life after esophagectomy and gastric tube reconstruction for cancer. J Visc Surg. 2011;148(5):e327-35.

\section{Submit your next manuscript to BioMed Central and we will help you at every step:}

- We accept pre-submission inquiries

- Our selector tool helps you to find the most relevant journal

- We provide round the clock customer support

- Convenient online submission

- Thorough peer review

- Inclusion in PubMed and all major indexing services

- Maximum visibility for your research

Submit your manuscript at www.biomedcentral.com/submit
C) Biomed Central 